\title{
Neuroprotection from Stem Cell-Derived Human Adipose Extracellular Vesicles Intranasally Administered 24 Hours After Stroke in Rats.
}

\section{Francieli Rohden}

Universidade Federal do Rio Grande do Sul

Luciele Varaschini Teixeira

Universidade Federal do Rio Grande do Sul

Luis Pedro Bernardi

Universidade Federal de Ciências da Saúde de Porto Alegre: Universidade Federal de Ciencias da Saude de Porto Alegre

Pâmela Lukasewicz

Universidade Federal do Rio Grande do Sul

Mariana Colombo

Universidade Federal do Rio Grande do Sul

Geciele Rodrigues Teixeira

Hospital de Clinicas de Porto Alegre

Fernanda dos Santos de Oliveira

Hospital de Clinicas de Porto Alegre

Elizabeth Obino Cirne Lima

Hospital de Clinicas de Porto Alegre

Fátima Costa Rodrigues Guma

Universidade Federal do Rio Grande do Sul

Diogo Onofre Souza ( $\square$ diogo.bioq@gmail.com )

Universidade Federal do Rio Grande do Sul https://orcid.org/0000-0002-4322-0404

\section{Research Article}

Keywords: Human Adipose Tissue Mesenchymal Stem Cells, Extracellular Vesicles, Experimental Ischemic Stroke, Intranasal Treatment, Neuroprotection

Posted Date: March 13th, 2021

DOI: https://doi.org/10.21203/rs.3.rs-300710/v1 
License: (c) (i) This work is licensed under a Creative Commons Attribution 4.0 International License. Read Full License 


\section{Abstract}

Ischemic stroke is a major cause of death and disability, demanding innovative and accessible therapeutic strategies. Approaches presenting an optimal period for therapeutic intervention and new treatment administration routes are promising tools for stroke treatment. We evaluated the potential neuroprotective properties of nasally administered human adipose tissue stem cells (hAT-MSCs)-derived extracellular vesicles (EVs) obtained from healthy individuals who underwent liposuction. A single intranasal EV $(200 \mu \mathrm{g} / \mathrm{kg})$ was administered $24 \mathrm{~h}$ after a focal permanent ischemic stroke in rats. A higher tropism of EVs was observed in the peri-infarct zone surrounding the infarct core. In the same brain region, there was a significant decrease in the infarct volume, improvement of the blood-brain barrier, and re-stabilization of vascularization. In addition, EVs recovered the impairment of long-term motor and behavioral performance induced by an ischemic stroke. Surprisingly, one single intranasal EVs administration reestablished: i) front paws symmetry, ii) short- and long-term memory, and iii) anxiety-like behavior. In line with the findings, our work highlights hAT-MSC-derived EVs as a promising therapeutic strategy for stroke.

\section{Introduction}

Stroke is a major cause of death and permanent disability worldwide, affecting health and financial capabilities [1, 2]. Ischemic stroke represents $~ 85 \%$ of stroke cases [3-6], in which approximately $80 \%$ cause contralateral upper limb paresis [7] and sensory function impairment [8]. In addition, clinical observations have shown that $20-50 \%$ of patients experience memory disorders $[9,10]$.

The pathophysiology of ischemic stroke is characterized by blood flow obstruction in a restricted brain region, forming an infarct nucleus surrounded by an area known as the penumbra region. Of note, this region can be reperfused [11], and animal models refer to the peri-infarct region [12]. Reperfusion of the penumbra/peri-infarct zone contributes to a reduction in the final infarct size and attenuation/reversal of neurological and behavioral deficits $[13,14]$. Therefore, therapeutic strategies focusing on penumbra region salvage have been intensively investigated [15]. Currently, the gold standard treatment for ischemic stroke is thrombolytic agents which focus on optimizing the reperfusion time in the penumbra region [16]. However, this strategy must be strictly applied within $4.5 \mathrm{~h}$ after the first symptoms [17]. In addition, reperfusion injury such as hemorrhage is the most dangerous collateral effect after thrombolysis $[18,19]$. Thus, thrombolytic treatment is contraindicated for a certain class of patients at risk for bleeding or the formation of large blood clots [20]. Additionally, some patients would be considered for endovascular therapy (mechanical thrombectomy), which could increase the maximum time to receive treatment up to $24 \mathrm{~h}$ after the first symptoms; however, this procedure requires qualified professionals and infrastructure to conduct imaging exams (computed tomography scan and angiogram computed tomography) $[18,21]$. Therefore, it is essential to develop new and accessible therapeutic strategies for ischemic stroke.

In vivo studies using rat models of brain ischemia demonstrated that treatment with mesenchymal stem cells (MSCs) increased the therapeutic window up to $24 \mathrm{~h}$ after ischemic insult [22-24]. Although MSCs 
therapy seems promising, it may cause some impacting damage such as immune rejection and risk of developing tumor tissue [25]. Thus, improvements in MSCs therapy have been made to optimize their efficacy. It is currently thought that the protective effects of MSCs are due to the release of extracellular vesicles (EVs). EVs are small double-membrane vesicles $(30-200 \mathrm{~nm}$ ) that are released by many cell types, which in physiological conditions mediate cell-to-cell communication [26]. Compared to MSCs, EVs have lower immunogenicity, decreasing the risk of obstructive vascular effects and secondary microvascular thrombosis and presenting a higher ability to cross the blood-brain barrier (BBB) $[27,28]$.

Previous experimental studies systemically administered EVs $24 \mathrm{~h}$ after ischemic stroke demonstrated increased angiogenesis, neurogenesis, and neurite remodeling, with long-term recovery in rats [29-32]. However, systemically administered EVs may be metabolized before reaching the brain tissue [33], being detected in other organs (such as the lungs, liver, and spleen) [34]. Thus, some studies have focused on a straightforward and noninvasive strategy to administer EVs targeting the brain as a potential strategy to treat brain disorders [35-37].

In this study, we investigated the neuroprotective effects of EVs released from human adipose tissue mesenchymal stem cells (hAT-MSCs) through a single intranasal administration $24 \mathrm{~h}$ after ischemic injury in rats. Specifically, we evaluated the short- and long-term effects of a permanent focal stroke model and the effects of EVs on forepaws symmetry, behavioral performance, anxiety-like behavior, brain infarct volume, BBB permeability, and brain formation of new blood vessels.

\section{Materials And Methods}

hAT-MSCs: sources, culture, and characterization. The cells were obtained from commercial and human sources.

Commercial hAT-MSCs: Cells were obtained from the POIETICS Bank Adipose-Derived Stem Cells (cat. \#PT-5006, donor 34464. The cell type was confirmed by the presence of clusters of differentiation (CDs), such as CD13, CD29, CD44, CD73, CD90, CD105, and CD166, and by the absence of CD14, CD31, and CD45. They were tested negatively for mycoplasma, bacteria, yeast, and fungi by the supplier company. A frozen vial containing $\sim 1 \times 106$ cells was thawed at $37^{\circ} \mathrm{C}$ and plated in a $25 \mathrm{~cm}^{2}$ flask (TPP). Cells were cultured in DMEM medium (Sigma) containing 10\% FBS (Cripion), 100 units $/ \mathrm{mL}$ penicillin (Gibco), 100 $\mu \mathrm{g} / \mathrm{mL}$ streptomycin (Gibco), $50 \mathrm{mg} / \mathrm{L}$ gentamicin (Sigma), and $2.5 \mathrm{mg} / \mathrm{L}$ fungizone (Sigma). After $24 \mathrm{~h}$, the debris and non-adherent cells were gently removed [36]. When adherent cells reached $80 \%$ confluence (passage1: P1), hAT-MSCs were detached with $0.25 \%$ trypsin $/ 1 \mathrm{mM}$ ethylenediaminetetraacetic acid (EDTA) (Sigma) and plated in flasks at a density of $1.5 \times 10^{4}$ cells $/ 75 \mathrm{~cm}^{2}$ (passage 2: P2). Cellular density was determined by manually counting the number of cells at each passage[38]. The cells were named cell $0(\mathrm{CO})$. CO was expanded under the above-described conditions and used only from the $4^{\text {th }}$ to $8^{\text {th }}$ passage $[29,38,39]$. 
Patient-derived hAT-MSCs: Cells were obtained from the subcutaneous adipose tissue of two 30-year-old women who underwent abdominal liposuction at the Hospital de Clínicas in Porto Alegre (University Hospital) RS, Brazil. The patients agreed to participate in the study and signed a consent form (GPPG 2018-0374). Fresh adipose tissue was washed with PBS buffer, minced, and digested for $1 \mathrm{~h}$ in $0.1 \%$ collagenase at $37^{\circ} \mathrm{C}$. The digestion process was stopped by the addition of Dulbecco's modified Eagle's medium (DMEM) containing 20\% fetal bovine serum (FBS), 100 units $/ \mathrm{mL}$ penicillin (Gibco), and 100 $\mu \mathrm{g} / \mathrm{mL}$ streptomycin (Gibco). The digested suspension was filtered through a $70 \mu \mathrm{m}$ nylon mesh cell filter to retain tissue debris. The filtered suspension was centrifuged at $400 \times \mathrm{g}$ for $5 \mathrm{~min}$. The stromal vascular fraction (pellet) was resuspended in DMEM $+20 \%$ FBS (Cripion) medium and cultured in a culture flask of $25 \mathrm{mc}^{2}$ (TPP) at $37^{\circ} \mathrm{C}$, with a humidified $5 \% \mathrm{CO}_{2}$ atmosphere. After $24 \mathrm{~h}$, non-adherent cells were gently removed [38]. When adherent cells reached $80 \%$ confluence (passage $0:$ P0), confluent cells (hAT-MSCs) were detached with $0.25 \%$ trypsin/ $1 \mathrm{mM}$ ethylenediaminetetraacetic acid (EDTA) (Sigma) and plated in flasks at a density of $1.5 \times 10^{4}$ cells $/ 75 \mathrm{~cm}^{2}$ (TPP) (passage1: P1). Cells were cultured in DMEM medium (Sigma) containing 10\% FBS (Cripion), 100 units/mL penicillin (Gibco), $100 \mu \mathrm{g} / \mathrm{mL}$ streptomycin (Gibco), gentamicin $50 \mathrm{mg} / \mathrm{L}$ (Sigma), and fungizone $(2.5 \mathrm{mg}$ ) (Sigma). These cells are named cell 1 - patient 1 (C1) and cell 2 - patient 2 (C2). $\mathrm{C} 1$ and $\mathrm{C} 2$ were expanded under the same conditions described above and used only from the $4^{\text {th }}$ to $8^{\text {th }}$ passage $[35,39]$.

C1 and C2 hAT-MSCs were characterized by immunofluorescence using flow cytometry and confocal microscopy.

Flow cytometry: hAT-MSCs were centrifuged (400xg for $5 \mathrm{~min}$ at room temperature), the cell pellet was resuspended in DMEM+10\% FBS, and the cells were counted in a Neubauer chamber. Shortly after, the cells were incubated with antibodies at a concentration of $1: 50$ for $4 \mathrm{~h}$ at $37^{\circ} \mathrm{C}$. Then, the cell suspensions were centrifuged at $400 \times \mathrm{g}$ for $5 \mathrm{~min}$ at room temperature, and cell pellets were resuspended in $200 \mu \mathrm{L}$ of PBS. Ten thousand events were analyzed using flow cytometry (BD FACSCalibur ${ }^{\mathrm{TM}}$ ) [40]. Cells, only in passage 4 (P4), were characterized as hAT-MSCs in the presence of CD: CD34 (FITC mouse anti-human CD34 BD Pharmingen), CD45 (Human CD45 FITC Conjugate, Invitrogen), CD 90 (P.E. Mouse Anti-Human CD90 BD Pharmingen), and CD105 (Huan CD105 R-PE conjugate, Invitrogen).

Confocal microscopy. An aliquot of $1 \times 10^{4}$ hAT-MSCs was placed on a slide and analyzed by immunofluorescence. Cells were maintained under culture conditions for $72 \mathrm{~h}$ to adhere to coverslips. Cells were then incubated for $4 \mathrm{~h}$ at $37^{\circ} \mathrm{C}$ with the same antibodies used for cytometry: CD34, CD45, CD90, and CD105, at a ratio of 1:500. The negative control was prepared by incubating only the secondary antibodies, Alexa Fluor 555 (Invitrogen) and Alexa Fluor 488 (Invitrogen). Cells were gently washed in a coverslip with PBS (four times) to remove excess antibodies, followed by fixation with PFA $4 \%$ for $2 \mathrm{~h}$. Cells were gently washed again with PBS, and the coverslips were fixed with Fluoromount (Sigma) onto a histological slide for further analysis. Images were acquired using an 8-bit grayscale confocal laser scanning microscope (Olympus FV1000). Approximately $10 \times 15$ sections with $.7 \mu \mathrm{m}$ thick confocal were captured parallel to the coverslip (XY sections) using a $\times 20$ objective (Olympus, U plan- 
super-apochromatic, UPLSAPO 60X). Z-stack reconstruction and analysis were conducted using ImageJ software (http://rsb.info.nih.gov/ij/).

Extracellular Vesicles (EVs) EVs isolation and purification: As cultured hAT-MSCs (P4-P8) reached 80\% confluence, DMEM+10\% FBS medium was replaced by DMEM FBS-free (to avoid isolated vesicles contamination by FBS proteins). After $72 \mathrm{~h}$ of culture, the medium was collected for vesicles isolation and the cells remained in culture. To recover from the stress caused by FBS removal, the remaining cells were supplemented with DMEM+10\% FBS for $72 \mathrm{~h}$ [29].

For EVs isolation, the medium was collected and centrifuged ( 3 times) at $4^{\circ} \mathrm{C}:\left(1^{\text {st. }}: 400 \times \mathrm{g}\right.$ for $15 \mathrm{~min}, 2^{\text {nd }}$ : $2000 \times \mathrm{g}$ for $15 \mathrm{~min}$, and $3^{\text {rd. }} 10,000 \times \mathrm{g}$ for $30 \mathrm{~min}$ ). The supernatants were filtered through a $0.22 \mu \mathrm{m}$ membrane. The isolation was completed by centrifugation $\left(100,000 \times \mathrm{g}\right.$ at $4{ }^{\circ} \mathrm{C}$ for $\left.2 \mathrm{~h}\right)$. The supernatant was discarded, PBS was used to wash the pellet containing EVs, and the cell suspension was centrifuged at $100,000 \times \mathrm{g}$ at $4{ }^{\circ} \mathrm{C}$ for $2 \mathrm{~h}$ [41]. Finally, the pellet was resuspended in $100 \mu \mathrm{L}$ of PBS and stored at -20 ${ }^{\circ} \mathrm{C}[38]$. EVs protein content was quantified using a bicinchoninic acid (BCA) assay (Thermo Scientific Pierce $^{\mathrm{TM}}$ ) [38]. The vesicles isolated from $\mathrm{CO}, \mathrm{C} 1$, and $\mathrm{C} 2$ cells were named EV0, EV1, and EV2, respectively.

EVs characterization: EVs were characterized by flow cytometry and the identification of membrane proteins CD63 and CD81 [42]. First, EVs were incubated with magnetic beads (Thermo Fisher Scientific, Invitrogen ${ }^{\text {TM }}$ ) coated with primary antibody CD63 (Exosome-Human CD63, Thermo Fisher Scientific - Invitrogen ${ }^{\mathrm{TM}}$ ) and CD81 (Exosome-Human CD81, Thermo Fisher Scientific - Invitrogen ${ }^{\mathrm{TM}}$ ) for $18 \mathrm{~h}$ at $4{ }^{\circ} \mathrm{C}$ under gentle stirring. For each preparation, $10 \mu \mathrm{L}$ of a $1 \mathrm{mg} / \mathrm{mL}$ EVs suspension was applied. To remove excess beads, EVs were washed with PBS: $2 \mathrm{~mL}$ of PBS was added for $5 \mathrm{~min}$, then the tube was placed in a magnet for $1 \mathrm{~min}$, and the supernatant was discarded. Then, CD63 (CD63 Anti-human Mouse, FITC, Clone: MEM-259, Invitrogen ${ }^{\mathrm{T}}{ }^{\text {}}$ ) and CD81 (P.E. Anti-Human Mouse CD81 Clone JS-81, BD Pharmingen ${ }^{\mathrm{T}}$ ) antibodies (without granules) were added to the solution containing the EVs + magnetic beads. After $1 \mathrm{~h}$ of incubation, the EVs were gently washed by placing the tube on a magnet for 1 min, discarding the supernatant. We added $2 \mathrm{~mL}$ of PBS (to remove excess antibody) for $5 \mathrm{~min}$ and again placed the tube on a magnet for $1 \mathrm{~min}$ and discarded the supernatant. Finally, the EVs were resuspended in $200 \mu \mathrm{L}$ PBS for analysis. Ten thousand events were analyzed by flow cytometry.

To measure the particle size and polydispersity index (PDI), we used photon correlation spectroscopy. The EVs suspension derived from hAT-MSCs $(50 \mu \mathrm{L})$ at $1 \mathrm{mg} / \mathrm{mL}$ was diluted in $1 \mathrm{~mL}$ of PBS. All analyses were performed in triplicate using a Malvern Nano-ZS90® (Malvern Instruments, England) at $25^{\circ} \mathrm{C}$.

EVs purity measurement: Transmission electron microscopy (TEM) analysis, using a direct examination technique, was used to evaluate EV purity and diameter sizes [37]. EVs suspension (10 $\mu \mathrm{L}), 1 \mathrm{mg} / \mathrm{mL}$ of protein, was aliquoted onto a grid covered with carbon film (formvar/carbon) and dried at room temperature. Uranyl was used as a contrast agent. The sample was analyzed by TEM at $120 \mathrm{Kv}$ (JEM 1200 Exll-JEOL). 
EVs Labeling: EVs were labeled with the red fluorescent membrane dye PKH26 (MINI26, Sigma). In brief, the EVs-containing PBS solution was centrifuged $100,000 \times \mathrm{g}$ for $2 \mathrm{~h}$ at $4{ }^{\circ} \mathrm{C}$, and the pellet was suspended with the diluent of the fluorescent kit. Filtered PKH26 $(4 \mathrm{mM})$ and EVs $(200 \mu \mathrm{g} / \mathrm{mL})$ were mixed at a ratio of $1: 1$ for $5 \mathrm{~min}$, followed by the addition of $5 \%$ BSA. To remove excess dye, the EVs were washed three times, $5 \mathrm{~mL}$ of PBS was added and centrifuged at $100,000 \times \mathrm{g}$ for $2 \mathrm{~h}$ at $4{ }^{\circ} \mathrm{C}$, and the supernatant was discarded. In the last centrifugation, the stained EVs pellet was suspended in PBS $(0.5 \mathrm{~mL})$. The solution was filtered through a $0.2 \mu \mathrm{m}$ membrane filter to remove dye aggregates [35].

Animals Adult (90-120 days old) male Wistar rats weighing 350-400 g were maintained under controlled light (12/12 $\mathrm{h}$ light/dark cycle), $22^{\circ} \mathrm{C} \pm 2{ }^{\circ} \mathrm{C}$, with water and food ad libitum. All procedures were performed following the Guide for the Care and Use of Laboratory Animals and the Brazilian Society for Neuroscience and Behavior recommendations for animal studies. The Ethics Committee for the Use of Animals at the Universidade Federal do Rio Grande do Sul (process number: 31888) approved this study. The schematic of the procedure is illustrated in Figure 1.

Focal permanent ischemia and sham procedures: Anesthetized animals (ketamine hydrochloride: 90 $\mathrm{mg} / \mathrm{kg}, 450 \mu \mathrm{L} / \mathrm{kg}$ i.p. and xylazine hydrochloride: $10 \mathrm{mg} / \mathrm{kg}, 300 \mu \mathrm{L} / \mathrm{kg}$ i.p.) were placed into a stereotaxic apparatus. After skin incision, the skull was exposed, and a craniotomy was performed by exposing the left frontoparietal cortex ( $+2 \mathrm{~mm}$ to $-6 \mathrm{~mm}$ A.P. and $-2 \mathrm{~mm}$ to $-4 \mathrm{~mm}$ M.L. from the bregma). A focal permanent ischemic lesion was induced by thermocoagulation of the motor and sensorimotor pial vessels [43-47]. Blood vessels were thermo-coagulated by placing a hot probe near the dura mater for 2 min, until a red-brown color indicated complete thermo-coagulation. Soon after, the skin was sutured, and the animals were placed on a heating pad at $37^{\circ} \mathrm{C}$ until full recovery from anesthesia. Animals from the sham group were subjected to the craniotomy mentioned above. Animals were randomly allocated to three treatment groups: sham, ischemic (ISC), and ischemic treated with EVs (ISC+EV).

Intranasal EVs treatment: Intranasal EVs treatment was performed $24 \mathrm{~h}$ after the ischemic or sham procedure. Sedated animals $\left(\mathrm{O}_{2}\right.$ flow rate at $0.8-1.0 \mathrm{~L} / \mathrm{min}$ with Isoflurane levels of 2.5-3.0 \%) slowly (during $20 \mathrm{sec}$ ) received into the nasal cavity a single $50 \mu \mathrm{L}$ of EVs (ISC+EVs) or $50 \mu \mathrm{L}$ PBS (Naive, Sham, ISC). The $200 \mu \mathrm{g} / \mathrm{kg}$ EVs dose was selected based on a dose/effect curve: ISC+PBS, ISC+100 $\mu \mathrm{g} / \mathrm{kg}$, ISC+200 $\mu \mathrm{g} / \mathrm{kg}$, and ISC+300 $\mu \mathrm{g} / \mathrm{kg}(\mathrm{n}=3)$.

Brain analysis Extracellular fluorescent vesicles (EVS) detection in rat brain: Distribution of EVs in rat brains was analyzed $18 \mathrm{~h}$ after intranasal administration of fluorescent EVs (PKH26-mini, Sigma) [32, 35, 37]. Anesthetized animals (ketamine hydrochloride: $90 \mathrm{mg} / \mathrm{kg}, 450 \mu \mathrm{L} / \mathrm{kg}$ i.p. and xylazine hydrochloride: $10 \mathrm{mg} / \mathrm{kg}, 300 \mu \mathrm{L} / \mathrm{kg}$ i.p.) were transcardially perfused using a peristaltic pump with PBS followed by perfusion with PFA 4\% (both $10 \mathrm{~mL} / \mathrm{min}, 100 \mathrm{~mL}$ ). Brains were dissected, immersed in PFA 4\% (pH 7.4), and stored for a maximum of 7 days at $4{ }^{\circ} \mathrm{C}$. Coronal brain sections $20 \mu \mathrm{m}$ thick were obtained using a vibratome (Leica, Wetzlar, Germany) at $+2.20 \mathrm{~mm}, 0,20 \mathrm{~mm}$ and $-1,88 \mathrm{~mm}$ of Bregma. Brain slices were mounted on glass slides and incubated for $5 \mathrm{~min}$ in the dark with $1 \mu \mathrm{g} / \mathrm{mL}$ Hoechst dye (33342 SigmaAldrich) in PBS to detect cell nuclei. The slices were washed with PBS (four times), and the slices were 
fixed with fluoro mount (Sigma). Slice images for counting EVs were acquired using an 8-bit grayscale confocal laser scanning microscope (Olympus FV1000). Approximately 10-15 sections with .7 $\mu \mathrm{m}$ thick confocal were captured parallel to the coverslip (XY sections) using a $\times 60$ objective (Olympus, $U$ plansuper-apochromatic, UPLSAPO 60X). Z-stack reconstruction and analysis to count the vesicles in the brain tissue were conducted using ImageJ software, and background noise was removed using the "subtract background" tool. Images were converted to binary masks using the default threshold option, and vesicles were counted with the "analyze particles" tool (size $=0.05-0.90 \mu \mathrm{m})$. These settings were programmed into a macro and used for all analyzed images (http://rsb.info.nih.gov/ij/) $(\mathrm{n}=3$ naive and $\mathrm{n}=5$ ischemic for each group, 3 sections per rat per group).

Short-term infarct volume: For the short-term evaluation of infarct volume, Naive, Sham, ISC, ISC+EV0, and ISC+EV2 groups were sedated $48 \mathrm{~h}$ after treatment $\left(\mathrm{O}_{2}\right.$ flow rate of $0.8-1.0 \mathrm{~A} \mathrm{~mL} / \mathrm{min}$ with isoflurane levels of 2.5-3.0\%) and culled. Coronal sections of the whole brain were sliced at $2 \mathrm{~mm}$ and immersed in $2 \%$ 2,3,5-Triphenyl-tetrazolium chloride (TTC). After 30 minutes of incubation at $37^{\circ} \mathrm{C}$, the slices were dipped in $4 \%$ buffered paraformaldehyde ( $\mathrm{pH} \mathrm{7.4)} \mathrm{for} 24$ hours. The infarct area was evaluated as an area devoid of red staining. Infarct volume was measured using ImageJ software [44] (3 rats/group, 6 sections/rat).

Brain Angiogenesis: After 42 days of treatment, animals from the Naïve, ISC, and ISC+EV2 groups were anesthetized and received intracardial injection of $50 \mathrm{mg} / \mathrm{mL}(500 \mu \mathrm{L})$ fluorescein isothiocyanate-dextran amine (Merck) to label brain blood vessels. Rat brains were removed, immediately fixed in PFA 4\%, and cut into $30 \mu \mathrm{m}$ coronal slices in a vibratome. Images were acquired using a fluorescence microscope (Nikon). The images were taken from the ipsilateral and contralateral sides in the Secondary Motor Cortex (M2) and somatosensory regions (SS) using the coordinates: $+2.20 \mathrm{~mm}, 0.2 \mathrm{~mm}$, and $-1.88 \mathrm{~mm}$ A.P. to Bregma (PAXINUS online Rat Brain Atlas: http://labs.gaidi.ca/rat-brain-atlas/) ( $n=3$ per group). Blood vessel parameters, such as the total length (sum of the length of segments, isolated elements, and branches in the analyzed area) and the number of branches (in the analyzed area), were quantified using the Angiogenesis Analyzer Plugin (Gilles Carpentier Research) ImageJ software (https://imagej.nih.gov/ij/).

BBB permeability Evans Blue in brain parenchyma: Naïve $(\mathrm{n}=3)$, Sham $(\mathrm{n}=3)$, ISC $(\mathrm{n}=3)$, and ISC + EV2 $(\mathrm{n}=3)$ animals were anesthetized $48 \mathrm{~h}$ after treatment (ketamine hydrochloride $-90 \mathrm{mg} / \mathrm{kg}, 450 \mu \mathrm{L} / \mathrm{kg}$ i.p., and xylazine hydrochloride $10 \mathrm{mg} / \mathrm{kg}, 300 \mu \mathrm{L} / \mathrm{kg}$ i.p.) and received $3 \mathrm{~mL} / \mathrm{kg}$ of Evans Blue (EB) solution ( $2 \%$ in saline) through the gingival artery (Supplementary information 1 ). After $1 \mathrm{~h}$, the animals were subjected to cardiac perfusion using a peristaltic pump (10 mL/min, with PBS, $100 \mathrm{~mL})$. The animals were culled, their brains were removed, weighed, and the whole brain was sliced at $2 \mathrm{~mm}$ for image acquisition for each slice. Then, all slices from each brain were macerated and homogenized in $2.5 \mathrm{~mL}$ of PBS and vortexed for $2 \mathrm{~min}$. For protein precipitation, $50 \%$ trichloroacetic acid $(2.5 \mathrm{~mL})$ was added to the homogenate, incubated for $12 \mathrm{~h}$ at $50{ }^{\circ} \mathrm{C}$, and centrifuged at $14,000 \times \mathrm{g}$ for $10 \mathrm{~min}$. The concentration of the blue color was measured using a spectrophotometer $(620 \mathrm{~nm})$. EB dye was expressed in $\mu \mathrm{g} / \mathrm{g}$ of brain tissue against a standard curve $[48,49]$. 
CSF albumin levels: An albumin assay was performed using high-performance liquid chromatography coupled to a fluorescence detector (HPLC-FLD). The CSF method was validated according to the FDA guidelines [50,51]. HPLC-FLD consisted of an L.C. Shimadzu system (Kyoto, Japan) equipped with a 20AT pump, a DGU-14A degasser, a thermostat for a CTO-10A column, and a fluorescence detector, R.F. 20A. Data acquisition and processing were performed using the L.C. Solution software. The FLD was set at $278 \mathrm{~nm}$ (excitation) and $335 \mathrm{~nm}$ (emission). An Agilent reversed-phase ZORBAX SB-C18 column ( $5 \mu \mathrm{m}$ particle size, $250 \times 4.6 \mathrm{~mm}$ i.d.) was used. The method was performed using the following gradient conditions: solvent $A\left(\mathrm{H}_{2} \mathrm{O}+0.1 \%\right.$ formic acid) and solvent $B$ (acetonitrile $(\mathrm{ACN})$ as follows: $A \rightarrow 65 \% B \rightarrow$ $35 \%$ ( $0-5 \mathrm{~min}$ ), $A \rightarrow 70 \% \mathrm{~B} \rightarrow 30 \%$ (5-10 $\mathrm{min}), A \rightarrow 65 \% \mathrm{~B} \rightarrow 35 \%$ (10-17 min). The flow rate was set at $0.7 \mathrm{~mL} / \mathrm{min}$. Sample preparation was performed by adding $10 \mu \mathrm{L}$ liquor in $40 \mu \mathrm{L}$ of $\mathrm{ACN}$ and mixing in a vortex. The solution was transferred to conical vials and $10 \mu \mathrm{L}$ was injected. Albumin stock solutions 1 $\mathrm{mg} / \mathrm{mL}$ in water were stored at $20 \pm 2{ }^{\circ} \mathrm{C}$. For each day of analysis, standard solutions of albumin were prepared at $0,1,0,5,1,10,50$, and $100 \mu \mathrm{g} / \mathrm{mL}$.

Behavioral evaluation Cylinder Task (CT.): The cylinder task, which allows the evaluation of motor sequelae caused by ischemic insult [52], was used to determine the motor symmetry of the front paws. Exploration of the apparatus by the rats was evaluated when they raised their bodies and contacted their paw(s) on the cylinder wall (20 movements were counted). The apparatus consisted of a transparent glass cylinder $20 \mathrm{~cm}$ in diameter and $30 \mathrm{~cm}$ in height. All animals were submitted to this task $2 \mathrm{~h}$ before surgery to verify basal forelimb symmetry. The CT was repeated on the $3^{\text {rd }}, 7^{\text {th }}, 14^{\text {th }}, 21^{\text {st }}, 28^{\text {th }}, 35^{\text {th }}$, and $42^{\text {nd }}$ days after E.V. treatment. The performance was recorded using ANY-Maze software (Stoelting Co., Wood Dale, IL, USA). The ipsilateral (to the lesion), contralateral, or both front paws preferences were counted in a blind analysis. The asymmetry of each animal was calculated using the following formula: asymmetry $=(\%$ of ipsilateral paw use $=$ ipsilateral paw use/sum ipsilateral + contralateral + use of both paws) - (\% of contralateral paw use $=$ contralateral paw use/sum of ipsilateral and contralateral paws). The asymmetry percentage is converted into a symmetry percentage [43]. Groups: Naïve $(n=6)$, ISC $(n=$ 22), ISC+EV0 $(n=17)$, ISC+EV1 $(n=16)$, and ISC+EV2 $(n=17)$. At the end of each task, the apparatus was cleaned using $70 \%$ ethanol solution.

Open Field Task (OFT): The open field task evaluates habituation to novelty (assessing short- and longterm memory-exploratory activity) and locomotor activity in an arena [53]. The apparatus consisted of a black cage measuring $50 \mathrm{~cm}$ in length $\times 50 \mathrm{~cm}$ in width $\times 50 \mathrm{~cm}$ in height. The sessions lasted $10 \mathrm{~min}$ (individually). The animals performed the task on days $7^{\text {th }}, 21^{\text {st }}$, and $42^{\text {nd }}$ days after EVs treatment. Shortterm memory (habituation to novelty) was evaluated considering the decrease in locomotion during the first 5 min of the $1^{\text {st }}$ session ( $7^{\text {th }}$ day). Long-term memory was evaluated considering the decrease in locomotion during the first minute through successive sessions (from the $1^{\text {st }}$ to the $3^{\text {rd }}$ session). Groups: Naïve $(n=8)$, Naïve+EVO $(n=7)$, ISC $(n=22)$, ISC+EVO $(n=17), \operatorname{ISC}+E V 1(n=16)$, and ISC+EV2 $(n=17)$. At the end of each session, the apparatus was cleaned with $70 \%$ ethanol solution. The task was recorded and analyzed using ANY-maze 6.1 software. 
Novel Object Recognition Task (NORT): The behavioral sessions lasting 10 min were performed on days $7^{\text {th }}, 21^{\text {st }}$, and $42^{\text {nd }}$ days after EVs treatment. At 90 min after the OFT session, Object Recognition (OR) short- and long-term memories were evaluated [54]. The animals were individually placed on the periphery of the arena for further exploration. Two identical familiar objects (FOs) were placed in the arena, and animals could explore them for $10 \mathrm{~min}$. Sniffing and touching the objects were considered exploratory behaviors. Ninety minutes after the training session, each animal was placed back into the arena to evaluate short-term memory. One of the two FOs used in the training session was replaced by a new distinct object (NO). Long-term memory was evaluated $24 \mathrm{~h}$ after the short-term memory task session when the animals were placed back in the arena with the same FO used in the training session and the first test session (short-term memory); however, the same NO was displaced to a different position. In all sessions, the time spent exploring the objects was recorded using ANY-maze 6.1 software. Results are expressed as a percentage of the time spent exploring each object. Animals that recognized the novel object (short-term memory) or its new position (long-term memory) explored more than $50 \%$ of the total exploration time of both objects. Groups: Naïve $(n=8)$, Naïve +EV0 $(n=7)$, ISC $(n=22)$, ISC+EV0 $(n=17)$, ISC+EV1 $(n=5)$, and ISC+EV2 $(n=16)$. At the end of each session, the apparatus was cleaned using $70 \%$ ethanol solution.

Elevated Plus-Maze Task (EPMT): The EPMT task is widely used to study anxiety-like behavior [55]. The apparatus had two open arms (50 cm long $\times 10 \mathrm{~cm}$ wide) and two closed arms $(50 \mathrm{~cm}$ long $\times 10 \mathrm{~cm}$ wide $\times 40 \mathrm{~cm}$ high), separated by a central platform $(5 \mathrm{~cm}$ long $\times 5 \mathrm{~cm}$ wide). The apparatus was placed 70 $\mathrm{cm}$ above the floor. The animals were kept in a red-light area for $1 \mathrm{~h}$ before starting the task. ANY-maze software was used to record behavioral performance for $5 \mathrm{~min}$. The percentage of time spent in the open and closed arms was also assessed. Anxiety-like behavior was considered as the increase of time spent on closed arms. Each animal was exposed this once on the $7^{\text {th }}$ day after treatment with EVs. At the end of each session, the equipment was cleaned with $70 \%$ alcohol.

Statistical Analysis The size of the brain lesion, BBB integrity, number of vesicles found in brain tissue, and angiogenesis analysis were evaluated by unpaired t-tests. Two-way RM ANOVA was applied for CT, followed by Sidak's multiple comparison test. Short-term memory was evaluated using an unpaired t-test. Long-term memory was evaluated using two-way ANOVA followed by Sidak's multiple comparison test. Unpaired t-tests were used for the NORT, with a theoretical average of $50 \%$. Data are reported as the mean \pm SD. All analyses were performed using GraphPad Prism version 6.0.

\section{Results}

Characterization of hAT-MSCs and EVs hAT-MSCs: Fig 2 shows that there is no single marker to characterize hADSCs, which is done by immunophenotyping based on the presence (> 70\%) of CD90 and CD105, associated with the absence $(<5 \%)$ of CD34 and CD45 [29]. Displacement of the fluorescence peak to the right side registers a positive value for the presence of protein markers. More than $70 \%$ of $\mathrm{C} 1$, $C 2$, and $C 3$ cells were positive for $C D 90$ and $C D 105$, while only $0.3 \%$ of the analyzed cells were positive 
for CD45 and CD34, which is a characteristic of these cells. The cells were characterized by fluorescence microscopy using the same markers.

Extracellular vesicles (EVs) Characterization: In Fig 3, EVs were detected inside the $\mathrm{C} 0$ cells by confocal microscopy through the presence of CD63 and CD81 marking (Fig 3a, 3b, and 3c). They were detected in the plasma membrane and cytoplasm near the nucleus. The released EVs (EV0, EV1, and EV2) were analyzed by measuring CD63 and CD81 staining using flow cytometry; more than $90 \%$ of the EVs presented CD63 and CD81 [42] (Fig 2d). The released EVs (EV0, EV1, and EV2) were also analyzed using a Zetasizer instrument, which indicated an average diameter of $140 \mathrm{~nm}$, with a polydispersity index (PDI) average of 0.3 , as shown in Fig $3 e$. The purity of the released suspension was confirmed using the TEMdirect technique. The suspension only consisted of released vesicles with a cylindrical morphology and electron-dense membranes (indicated by the black arrow in Fig $3 f$ ).

Stroke damage and EVs neuroprotection EVs administration on motor neuroprotection: Fig 4, Dose curve of EV1 administration, and motor neuroprotection. The cylinder task (CT) measured front paw symmetry and was applied to identify the lowest dose to be used for EV stroke treatment. All animals underwent the CT task $24 \mathrm{~h}$ before stroke (day -1 ). Of note, only animals with $~ 100 \%$ front paw symmetry were included in the study. Furthermore, we performed intranasal administration of EVO or vehicle $24 \mathrm{~h}$ after stroke. Indeed, $72 \mathrm{~h}$ after stroke, all ISC groups, treated or not, presented a mean symmetry of $30 \%$. Interestingly, animals treated with EVs showed gradual improvement in symmetry of the front paws compared to untreated animals in a time-and dose-dependent manner; on the $42^{\text {nd }}$ day after intranasal administration, animals in the vehicle and treated EVs $(100 \mu \mathrm{g} / \mathrm{kg}, 200 \mu \mathrm{g} / \mathrm{kg}$, or $300 \mu \mathrm{g} / \mathrm{kg})$ groups presented symmetry recovery of $58 \% \pm 6 \%, 67 \% \pm 4 \%, 87 \% \pm 8 \%$, and $82 \% \pm 3 \%$, respectively. Animals receiving $200 \mu \mathrm{g} / \mathrm{kg}$ or 300 $\mu \mathrm{g} / \mathrm{kg}$ did not differ from the Naïve group from the $21^{\text {st }}$ day after treatment with VES $(95 \% \pm 3)$, suggesting a total recovery of symmetry. In keeping with this, a dose of $200 \mu \mathrm{g} / \mathrm{kg} 24 \mathrm{~h}$ after stroke was selected for further experiments.

Effect of $200 \mu \mathrm{g} / \mathrm{kg}$ EVs treatment on neuromotor recovery: In Fig 5, EV0, EV1, and EV2 treatments, applied $24 \mathrm{~h}$ after stroke, caused a time-dependent recovery of front paw symmetry from the $7^{\text {th }}$ day after treatment (ISC: $31 \% \pm 11$, ISC+EV0: 63\% \pm 15 , ISC+EV1: 67\% \pm 13 , ISC+EV2: $66 \% \pm 13$ symmetry, $\mathrm{p}<0.0001$ ), reaching total recovery until the $28^{\text {th }}$ day (ISC: $43 \% \pm 14$, ISC+EV0: $82 \% \pm 9$, ISC+EV1: $76 \% \pm 9$, ISC+EV2: $82 \%$ \pm 6 symmetry, $\mathrm{p}<0.0001)$. On the $42^{\text {nd }}$ day (last evaluation), the $S C I+I S C+E V s$ group had similar symmetry to the Naïve group (Naïve: $95 \% \pm 02$, ISC+EV0: $86 \% \pm 10$, ISC+EV1: $86 \% \pm 05$, ISC+EV2: $80 \% \pm 05$ symmetry).

Short-term infarct volume: In Fig 6, The infarct volume was evaluated $72 \mathrm{~h}$ after the ischemic insult (48 $\mathrm{h}$ after treatment). Treatment with $200 \mu \mathrm{g} / \mathrm{kg}$ EVs significantly decreased the infarct volume (ISC $\times$ ISC+EV0 $p<0.05$, ISC $\times$ ISC+EV2, $p<0.05)$.

BBB permeability: As illustrated in Fig 7, stroke affected BBB permeability, an effect partially attenuated by EVs treatment. This EVs neuroprotective effect was demonstrated by Evans blue dye penetration into 
the brain parenchyma (Fig 7a and 7b) and by an increase in CSF albumin levels (Fig 7c), (ISC $\times$ ISC+EV3, $p<0.05$, for both parameters).

EVs detection in rat brain: In Fig 8, the distribution of EV0 $(200 \mu \mathrm{g} / \mathrm{kg})$ in the cortical brain was evaluated. The images were acquired in the position $2.2 \mathrm{~mm}, 0.2 \mathrm{~mm}$, and $-1.88 \mathrm{~mm}$ A.P. of Bregma (Fig. 8a). The regions were: 2 ipsilateral peri-infarct regions and their contralateral equivalents, specifically the supplementary motor cortex (M2) and somatosensory regions (SS). Remarkably, there was no homogeneous distribution of the EVs. In the ISC group, the M2-ipsilateral (M2-I) and M2-contralateral (M2-C) regions had a greater number of vesicles compared to the naïve animals and the ISC SS-ipsilateral (SS-I) and ISC SS-Contralateral (SS-C) (Fig 8b; $p<0.0001)$. Fig 4C-H shows representative images of these findings.

Open Field Task (OFT): In Fig 9, this task evaluates the habituation to novelty. Animals were subjected to three sequential OFT sessions on days $7^{\text {th }}, 21^{\text {st }}$ and $42^{\text {nd }}$ after EVs treatment. All groups presented shortterm memory (evaluated only in the $1^{\text {st }}$ exhibition). Naïve groups also had long-term memory, which was impaired by stroke; EV0, EV1, and EV2 treatment abolished this effect.

Novel Object Recognition Task (NORT): In Fig 10, NORT was used to evaluate short- and long-term memory of object recognition (OR) on days $7^{\text {th }}, 21^{\text {st }}$, and $42^{\text {nd }}$ after EVO, EV1, or EV2 treatment. Stroke impaired both short- and long-term memory, which was abolished by EVs treatment.

Elevated Plus-maze Task (EPMT): In Fig 11, the elevated plus-maze task is widely used to evaluate anxiety-like behavior. The task was performed on the $7^{\text {th }}$ day after treatment with EVs. ISC animals spent more time on the closed arms compared to the other groups, indicating that stroke-induced an anxiogenic-like effect. Interestingly, anxiety-like behavior due to stroke was completely abolished by EVO and EV1 treatment.

Brain angiogenesis: Fig 12 shows that stroke decreased the number of branches and the total length of blood vessels in the cortical M2-I region (Fig 12b and 12c). The EV treatment abolished the reduction in the number of branches. Figures $12 \mathrm{~d} /-12 \mathrm{i}$ show representative images of $\mathrm{M} 2$ regions. In the SS regions, there was no difference among the groups (Supplementary Information 2).

\section{Discussion}

The two available strategies for stroke treatment are thrombolytic agents and the mechanical removal of the thrombus. However, in both cases, accessibility may be limited. Thrombolytic agents must be strictly applied within $4.5 \mathrm{~h}$ after the first symptoms [15], while specialized equipment and highly trained people are required to remove the thrombus [19]. Therefore, the search for innovative and more accessible treatment strategies for stroke is important.

In this study, we demonstrated for the first time that intranasal hAT-MSC-derived EVs offer a broader early intervention opportunity ( $24 \mathrm{~h}$ after stroke), pointing to a potentially valuable stroke treatment strategy. 
Although studies have shown the neuroprotective effects of MSC-derived EVs on stroke [30, 32, 34], most of them apply systemic administration, a protocol in which EVs are detected in organs other than the brain, such as the lungs, liver, and spleen [32,33], where they may be metabolized before reaching the cerebral parenchyma [56]. In these studies, EVs were identified in brain regions, but no study has compared the number of EVs among regions [37, 56, 57]; thus, the EVs tropism for specific brain regions has not been previously reported.

Indeed, our findings demonstrated a non-homogenous distribution in the ischemic group: ipsi- and contralateral M2 peri-infarct regions contained more EVs than the SS regions (and also compared to the M2 and SS regions of naïve animals), indicating a higher EVs tropism in the peri-infarct region. These results are in accordance to previous studies, which have focused on stroke treatment strategies targeting the periinfarct region, aiming to stimulate angiogenesis $[58,59]$ and modulate BBB permeability $[33,59]$.

Clinical data from stroke patients have shown that behavioral and motor impairments are dependent on the brain regions where the infarct core and penumbra zone are developed [3]. Accordingly, our and other research groups have already shown that in the ischemic stroke rat model used here, the core and periinfarct regions are located in the prefrontal cortex and hippocampus [43-47], and brain structures involved in neuromotor and memory modulation $[60,61]$.

Here, our stroke model caused a localized BBB impairment (acutely measured by Evans blue) and a decrease in vascularization (chronically measured), both specifically in peri-infarct regions. Interestingly, higher EVs tropism was observed in the same peri-infarct regions, where BBB recovery and vascularization improvement were demonstrated. This association points to a potential role of hAT-MSCderived EVs in brain-located tissue repair, thus promoting motor and behavioral recovery.

Stimulation of angiogenesis has been shown to improve neurological and motor function in animal stroke models $[62,63]$, an effect currently acknowledged as an outcome of EVs transfer of protein, mRNA, and miRNA to endothelial cells [64], regulating proteins expression [65]. BBB impairment in ischemic stroke has also been documented [66], but its involvement in EVs therapeutic strategies has not been previously reported.

We believe that our work sheds light on a new and straightforward therapeutic strategy for focal permanent stroke treatment by utilizing hAT-MSCs from healthy individuals as a source for EVs. In addition, intranasal hAT-MSC-derived EVs administration $24 \mathrm{~h}$ after brain injury-induced a long-term neuroprotective effect, offering a remarkably broader therapeutic time window compared to current standard systemic routes. Taken together, these findings suggest a potential therapeutic strategy for patients with focal permanent ischemic stroke.

\section{Declarations}

\section{Funding}


The authors disclose receipt of the following financial support for the research, authorship, and/or publication of this article: This study was funded by the Instituto Nacional de Ciência e Tecnologia INCT-EN (2014 - 465671/2014-4), Conselho Nacional de Desenvolvimento Científico e Tecnológico CNPq, Ministério da Saúde, Coordenação de Aperfeiçoamento de pessoal de Nível Superior - CAPES, Fundação de Amparo à pesquisa do Estado do Rio Grande do Sul - FAPERGS, Universidade Federal do Rio Grande do Sul - UFRGS.

\section{Declaration of conflicting interests}

The authors declare no potential conflicts of interest concerning the research, authorship, and/or publication of this article.

\section{Availability of data and material}

The authors assume the availability of data and materials.

\section{Author contributions}

All authors contributed to all stages of this work and have read and approved the final manuscript.

\section{Compliance with ethical standards}

The study was performed in accordance to the ethical standards laid down in the 1964 Declaration of Helsinki and its later amendments or comparable ethical standards. All animal procedures were performed following the Guide for the Care and Use of Laboratory Animals and the Brazilian Society for Neuroscience and Behavior recommendations for animal studies. The Ethics Committee for the Use of Animals at the Universidade Federal do Rio Grande do Sul (process number: 31888) approved this study. The animals were followed up after the surgery, and signs of pain, discomfort, inflammation, and any other symptoms that indicate the animals' suffering were observed; after the surgery, the animals was euthanized, thus avoiding their its suffering (humanitarian endpoint).

\section{Consent to participate}

All participants who donated adipose tissue for cell isolation signed a free and informed consent form as recommended and approved by the Research and Graduate Group (Grupo de Pesquisa e Pós-Graduação: GPPG 2018-0374) and Research Ethics Committee (Comitê de Ética em Pesquisa CAEE:

94521618.4.0000.5327) of the Experimental Research Center at Hospital de Clínicas de Porto Alegre.

This document described the entire objective of the research and that these data could be published in a scientific journal, maintaining the confidentiality of the participants' data (anonymous donation).

Consent for Publication: Not applicable.

Acknowledgments: Not applicable. 


\section{References}

1. World Health Organization (2018) WHO - The top 10 causes of death. In: 24 Maggio. http://www.who.int/en/news-room/fact-sheets/detail/the-top-10-causes-of-death

2. Tarver T (2014) Heart Disease and Stroke Statistics-2014 Update: a Report From the American Heart Association

3. Powers WJ, Rabinstein AA, Ackerson T et al (2019) Guidelines for the early management of patients with acute ischemic stroke: 2019 update to the 2018 guidelines for the early management of acute ischemic stroke a guideline for healthcare professionals from the American Heart Association/American Stroke A

4. Surawan J, Sirithanawutichai T, Areemit S et al (2018) Prevalence and factors associated with memory disturbance and dementia after acute ischemic stroke. Neurol Int 10:83-89. https://doi.org/10.4081/ni.2018.7761

5. Mitchell AJ, Sheth B, Gill J et al (2017) Prevalence and predictors of post-stroke mood disorders: A meta-analysis and meta-regression of depression, anxiety and adjustment disorder. Gen Hosp Psychiatry 47:48-60. https://doi.org/10.1016/j.genhosppsych.2017.04.001

6. Tan HH, Xu J, Teoh HL et al (2017) Decline in changing montreal cognitive assessment (MoCA) scores is associated withpost-stroke cognitive decline determined by a formal neuropsychological evaluation. PLoS One 12:3-6. https://doi.org/10.1371/journal.pone.0173291

7. Tomašević Todorović S, Kopčanski S, Mikov A et al (2015) Functional Status of Patients After Stroke. Med Pregl 68:181-186. https://doi.org/10.2298/MPNS1506181T

8. Hatem SM, Saussez G, della Faille M et al (2016) Rehabilitation of motor function after stroke: A multiple systematic review focused on techniques to stimulate upper extremity recovery. Front Hum Neurosci 10:1-22. https://doi.org/10.3389/fnhum.2016.00442

9. Akyurekli C, Le Y, Richardson RB et al (2015) A Systematic Review of Preclinical Studies on the Therapeutic Potential of Mesenchymal Stromal Cell-Derived Microvesicles. Stem Cell Rev Reports 11:150-160. https://doi.org/10.1007/s12015-014-9545-9

10. Mellon L, Brewer L, Hall P et al (2015) Cognitive impairment six months after ischaemic stroke: A profile from the ASPIRE-S study. BMC Neurol 15:1-9. https://doi.org/10.1186/s12883-015-0288-2

11. Donnan GA, Baron JC, Ma H, Davis SM (2009) Penumbral selection of patients for trials of acute stroke therapy. Lancet Neurol 8:261-269. https://doi.org/10.1016/S1474-4422(09)70041-9

12. Ren $C$, Yao Y, Han R et al (2018) Cerebral ischemia induces angiogenesis in the peri-infarct regions via Notch1 signaling activation. Exp Neurol 304:30-40.

https://doi.org/10.1016/j.expneurol.2018.02.013

13. Lo EH (2008) A new penumbra: Transitioning from injury into repair after stroke. Nat Med 14:497500. https://doi.org/10.1038/nm1735

14. Uzdensky AB (2019) Apoptosis regulation in the penumbra after ischemic stroke: expression of proand antiapoptotic proteins. Apoptosis 24:687-702. https://doi.org/10.1007/s10495-019-01556-6 
15. Baron JC (2018) Protecting the ischaemic penumbra as an adjunct to thrombectomy for acute stroke. Nat Rev Neurol 14:325-337. https://doi.org/10.1038/s41582-018-0002-2

16. Rabinstein AA (2017) Tratamiento Agudo De Evc Isquemico. Continuum (N Y) 62-81

17. Fonarow GC, Smith EE, Saver JL et al (2011) Timeliness of tissue-type plasminogen activator therapy in acute ischemic stroke: Patient characteristics, hospital factors, and outcomes associated with door-to-needle times within 60 minutes. Circulation 123:750-758.

https://doi.org/10.1161/CIRCULATIONAHA.110.974675

18. Anttila JE, Whitaker KW, Wires ES et al (2017) Role of microglia in ischemic focal stroke and recovery: focus on Toll-like receptors. Prog Neuro-Psychopharmacology Biol Psychiatry 79:3-14. https://doi.org/10.1016/j.pnpbp.2016.07.003

19. Wang X, Tsuji K, Lee SR et al (2004) Mechanisms of hemorrhagic transformation after tissue plasminogen activator reperfusion therapy for ischemic stroke. Stroke 35:2726-2730. https://doi.org/10.1161/01.STR.0000143219.16695.af

20. Brinjikji W, Rabinstein AA, McDonald JS, Cloft HJ (2014) Socioeconomic disparities in the utilization of mechanical thrombectomy for acute ischemic stroke in US hospitals. Am J Neuroradiol 35:553556. https://doi.org/10.3174/ajnr.A3708

21. Nogueira RG, Jadhav AP, Haussen DC et al (2018) Thrombectomy 6 to 24 Hours after Stroke with a Mismatch between Deficit and Infarct. N Engl J Med 378:11-21. https://doi.org/10.1056/nejmoa1706442

22. Hosseini SM, Farahmandnia M, Razi Z et al (2015) 12 Hours After Cerebral Ischemia Is the Optimal Time for Bone Marrow Mesenchymal Stem Cell Transplantation. Neural Regen Res 10:904-908. https://doi.org/10.4103/1673-5374.158354

23. Xu Y, Du SW, Yu XG et al (2014) Human bone marrow mesenchymal stem cell transplantation attenuates axonal injury in stroke rats. Neural Regen Res 9:2053-2058. https://doi.org/10.4103/1673-5374.147930

24. Gómez-De Frutos MC, Laso-Garciá F, Diekhorst L et al (2019) Intravenous delivery of adipose tissuederived mesenchymal stem cells improves brain repair in hyperglycemic stroke rats. Stem Cell Res Ther 10:1-13. https://doi.org/10.1186/s13287-019-1322-x

25. Ridge SM, Sullivan FJ, Glynn SA (2017) Mesenchymal stem cells: Key players in cancer progression. Mol Cancer 16:1-10. https://doi.org/10.1186/s12943-017-0597-8

26. Camussi G, Deregibus MC, Bruno $S$ et al (2010) Exosomes/microvesicles as a mechanism of cell-tocell communication. Kidney Int 78:838-848. https://doi.org/10.1038/ki.2010.278

27. Chen CC, Liu L, Ma F et al (2016) Elucidation of Exosome Migration Across the Blood-Brain Barrier Model In Vitro. Cell Mol Bioeng 9:509-529. https://doi.org/10.1007/s12195-016-0458-3

28. Chen J, Chopp M (2018) Exosome therapy for stroke. Stroke 49:1083-1090. https://doi.org/10.1161/STROKEAHA.117.018292

29. Ni H, Yang S, Siaw-Debrah F et al (2019) Exosomes derived from bone mesenchymal stem cells ameliorate early inflammatory responses following traumatic brain injury. Front Neurosci 13:1-10. 
https://doi.org/10.3389/fnins.2019.00014

30. Han Y, Seyfried D, Meng Y et al (2019) Multipotent mesenchymal stromal cell-derived exosomes improve functional recovery after experimental intracerebral hemorrhage in the rat. J Neurosurg 131:290-300. https://doi.org/10.3171/2018.2.JNS171475

31. Williams AM, Dennahy IS, Bhatti UF et al (2019) Mesenchymal Stem Cell-Derived Exosomes Provide Neuroprotection and Improve Long-Term Neurologic Outcomes in a Swine Model of Traumatic Brain Injury and Hemorrhagic Shock. J Neurotrauma 36:54-60. https://doi.org/10.1089/neu.2018.5711

32. Otero-Ortega L, Laso-García F, Del C Gómez-De Frutos M, et al (2017) White matter repair after extracellular vesicles administration in an experimental animal model of subcortical stroke. Sci Rep 7:1-11. https://doi.org/10.1038/srep44433

33. Yang J, Zhang X, Chen X et al (2017) Exosome Mediated Delivery of miR-124 Promotes Neurogenesis after Ischemia. Mol Ther - Nucleic Acids 7:278-287. https://doi.org/10.1016/j.omtn.2017.04.010

34. Otero-Ortega L, Gómez de Frutos MC, Laso-García F et al (2018) Exosomes promote restoration after an experimental animal model of intracerebral hemorrhage. J Cereb Blood Flow Metab 38:767-779. https://doi.org/10.1177/0271678X17708917

35. Longa Q, Upadhya D, Hattiangady B et al (2017) Intranasal MSC-derived A1-exosomes ease inflammation, and prevent abnormal neurogenesis and memory dysfunction after status epilepticus. Proc Natl Acad Sci U S A 114:E3536-E3545. https://doi.org/10.1073/pnas.1703920114

36. Kodali M, Castro OW, Kim DK et al (2020) Intranasally administered human msc-derived extracellular vesicles pervasively incorporate into neurons and microglia in both intact and status epilepticus injured forebrain. Int J Mol Sci 21:. https://doi.org/10.3390/ijms21010181

37. Perets N, Betzer O, Shapira R et al (2019) Golden Exosomes Selectively Target Brain Pathologies in Neurodegenerative and Neurodevelopmental Disorders. Nano Lett 19:3422-3431. https://doi.org/10.1021/acs.nanolett.8b04148

38. Ohta $Y$, Takenaga $M$, Hamaguchi A et al (2018) Isolation of adipose-derived stem/stromal cells from cryopreserved fat tissue and transplantation into rats with spinal cord injury. Int J Mol Sci 19:. https://doi.org/10.3390/ijms19071963

39. Nalamolu KR, Venkatesh I, Mohandass A et al (2019) Exosomes treatment mitigates ischemic brain damage but does not improve post-stroke neurological outcome. Cell Physiol Biochem 52:12801291. https://doi.org/10.33594/000000090

40. Trinh NT, Yamashita T, Tu TC et al (2016) Microvesicles enhance the mobility of human diabetic adipose tissue-derived mesenchymal stem cells in vitro and improve wound healing in vivo. Biochem Biophys Res Commun 473:1111-1118. https://doi.org/10.1016/j.bbrc.2016.04.025

41. Scholl JN, De Fraga Dias A, Pizzato PR et al (2020) Characterization and antiproliferative activity of glioma-derived extracellular vesicles. Nanomedicine 15:1001-1018. https://doi.org/10.2217/nnm2019-0431 
42. Gurunathan $\mathrm{S}$, Kang $\mathrm{M}-\mathrm{H}$, Jeyaraj $\mathrm{M}$ et al (2019) Review of the Isolation, Characterization, Biological Function, and Multifarious Therapeutic Approaches of Exosomes. Cells 8:307. https://doi.org/10.3390/cells8040307

43. de Vasconcelos dos Santos A, da Costa Reis J, Diaz Paredes B et al (2010) Therapeutic window for treatment of cortical ischemia with bone marrow-derived cells in rats. Brain Res 1306:149-158. https://doi.org/10.1016/j.brainres.2009.09.094

44. Teixeira LV, Almeida RF, Rohden F et al (2018) Neuroprotective Effects of Guanosine Administration on In Vivo Cortical Focal Ischemia in Female and Male Wistar Rats. Neurochem Res 43:1476-1489. https://doi.org/10.1007/s11064-018-2562-3

45. Nonose Y, Gewehr PE, Almeida RF et al (2018) Cortical Bilateral Adaptations in Rats Submitted to Focal Cerebral Ischemia: Emphasis on Glial Metabolism. Mol Neurobiol 55:2025-2041. https://doi.org/10.1007/s12035-017-0458-x

46. Hansel G, Tonon AC, Guella FL et al (2015) Guanosine Protects Against Cortical Focal Ischemia. Involvement of Inflammatory Response. Mol Neurobiol 52:1791-1803. https://doi.org/10.1007/s12035-014-8978-0

47. Hansel G, Ramos DB, Delgado CA et al (2014) The potential therapeutic effect of guanosine after cortical focal ischemia in rats. PLoS One 9:1-10. https://doi.org/10.1371/journal.pone.0090693

48. Wang HL, Lai TW (2014) Optimization of Evans blue quantitation in limited rat tissue samples. Sci Rep 4:1-7. https://doi.org/10.1038/srep06588

49. Dal-Pizzol F, Rojas HA, Dos Santos EM et al (2013) Matrix metalloproteinase-2 and metalloproteinase-9 activities are associated with blood-brain barrier dysfunction in an animal model of severe sepsis. Mol Neurobiol 48:62-70. https://doi.org/10.1007/s12035-013-8433-7

50. European medicines agency (2012) Guideline on bioanalytical method validation guideline on bioanalytical method validation

51. FDA (2018) Guidance for industry: bioanalytical method validation. 1-44

52. MacRae I (2011) Preclinical stroke research - Advantages and disadvantages of the most common rodent models of focal ischaemia. Br J Pharmacol 164:1062-1078. https://doi.org/10.1111/j.14765381.2011.01398.x

53. Almeida RF de, Ganzella M, Machado DG et al (2017) Olfactory bulbectomy in mice triggers transient and long-lasting behavioral impairments and biochemical hippocampal disturbances. Prog NeuroPsychopharmacology Biol Psychiatry 76:1-11. https://doi.org/10.1016/j.pnpbp.2017.02.013

54. Figueiredo CP, Clarke JR, Ledo JH et al (2013) Memantine rescues transient cognitive impairment caused by high-molecular-weight $A \beta$ oligomers but not the persistent impairment induced by lowmolecular-weight oligomers. J Neurosci 33:9626-9634. https://doi.org/10.1523/JNEUROSCI.048213.2013

55. Almeida RF, Cereser VH, Faraco RB et al (2010) Systemic administration of GMP induces anxiolyticlike behavior in rats. Pharmacol Biochem Behav 96:306-311. https://doi.org/10.1016/j.pbb.2010.05.022 
56. Dabrowska S, Andrzejewska A, Strzemecki D et al (2019) Human bone marrow mesenchymal stem cell-derived extracellular vesicles attenuate neuroinflammation evoked by focal brain injury in rats. $J$ Neuroinflammation 16:1-15. https://doi.org/10.1186/s12974-019-1602-5

57. András IE, Toborek M (2016) Extracellular vesicles of the blood-brain barrier. Tissue Barriers 4:1-6. https://doi.org/10.1080/21688370.2015.1131804

58. Cirillo C, Brihmat N, Castel-Lacanal E et al (2020) Post-stroke remodeling processes in animal models and humans. J Cereb Blood Flow Metab 40:3-22. https://doi.org/10.1177/0271678X19882788

59. Rust $R$ (2020) Insights into the dual role of angiogenesis following stroke. J Cereb Blood Flow Metab 40:1167-1171. https://doi.org/10.1177/0271678X20906815

60. Morici JF, Bekinschtein P, Weisstaub NV (2015) Medial prefrontal cortex role in recognition memory in rodents. Behav Brain Res 292:241-251. https://doi.org/10.1016/j.bbr.2015.06.030

61. Zhou LYY, Wright TE, Clarkson AN (2016) Prefrontal cortex stroke induces delayed impairment in spatial memory. Behav Brain Res 296:373-378. https://doi.org/10.1016/j.bbr.2015.08.022

62. Slevin M, Kumar P, Gaffney J et al (2006) Can angiogenesis be exploited to improve stroke outcome? Mechanisms and therapeutic potential. Clin Sci 111:171-183. https://doi.org/10.1042/CS20060049

63. Kanazawa M, Takahashi T, Ishikawa M et al (2019) Angiogenesis in the ischemic core: A potential treatment target? J Cereb Blood Flow Metab 39:753-769.

https://doi.org/10.1177/0271678X19834158

64. Todorova D, Simoncini S, Lacroix R et al (2017) Extracellular vesicles in angiogenesis. Circ Res 120:1658-1673. https://doi.org/10.1161/CIRCRESAHA.117.309681

65. Gangadaran P, Rajendran RL, Lee HW et al (2017) Extracellular vesicles from mesenchymal stem cells activates VEGF receptors and accelerates recovery of hindlimb ischemia. J Control Release 264:112-126. https://doi.org/10.1016/j.jconrel.2017.08.022

66. Yang C, Hawkins KE, Doré S, Candelario-Jalil E (2019) Neuroinflammatory mechanisms of bloodbrain barrier damage in ischemic stroke. Am J Physiol - Cell Physiol 316:C135-C153. https://doi.org/10.1152/ajpcell.00136.2018

\section{Figures}

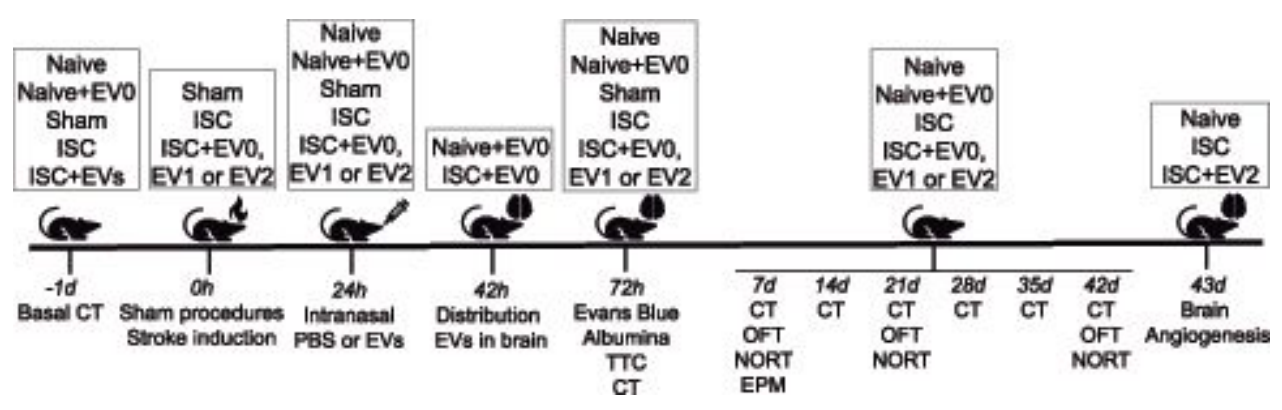

\section{Figure 1}


Experimental scheme. The animals received $50 \mu \mathrm{l}$ PBS or EVs by nostril $24 \mathrm{~h}$ after surgery. TTC: 2,3,5Triphenyl-tetrazolium chloride; CT: Cylinder Task; OFT: Open Field Task; NORT: Novel Object Recognition Task. EPMT: Elevated Plus Maze Task; Naïve: naïve group; Sham: Sham group; ISC: ischemic group; ISC+EV0, EV1, EV2: ISC+Vesicles 1, 2, 3
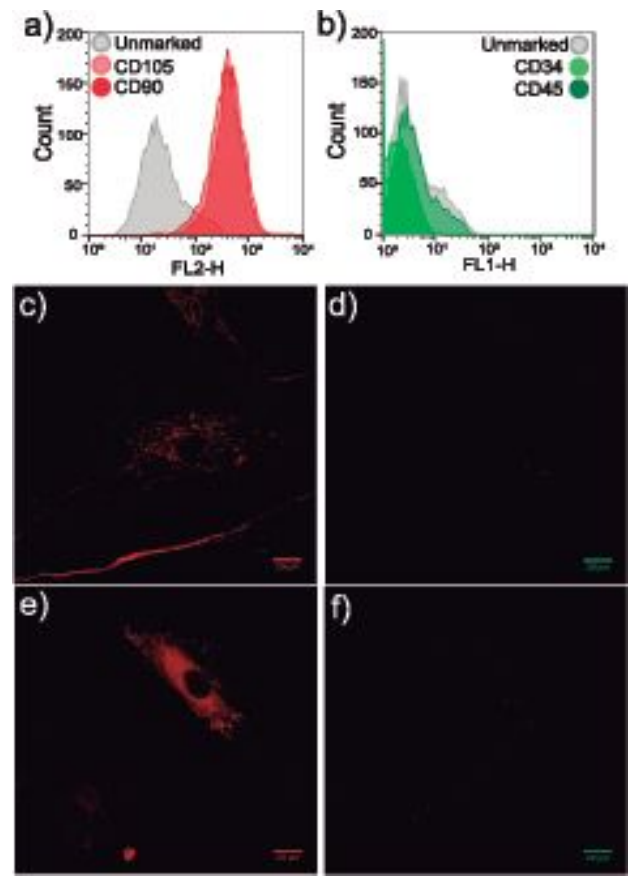

\section{Figure 2}

Representative images of cells by flow cytometry and fluorescence microscopy with CD labeling specific for hAT-MSCs. a) CD105 and CD90 (marking 70\% of the cells). b) CD34 and CD45 (non-expression in both cells) c) to f) Representative images of cells from fluorescence microscopy, 40x objective: c) CD90 (red); d) CD45 (green); e) CD105 (red); f) CD34 (green). N=3, Scale bars: 20 $4 \mathrm{~m}$
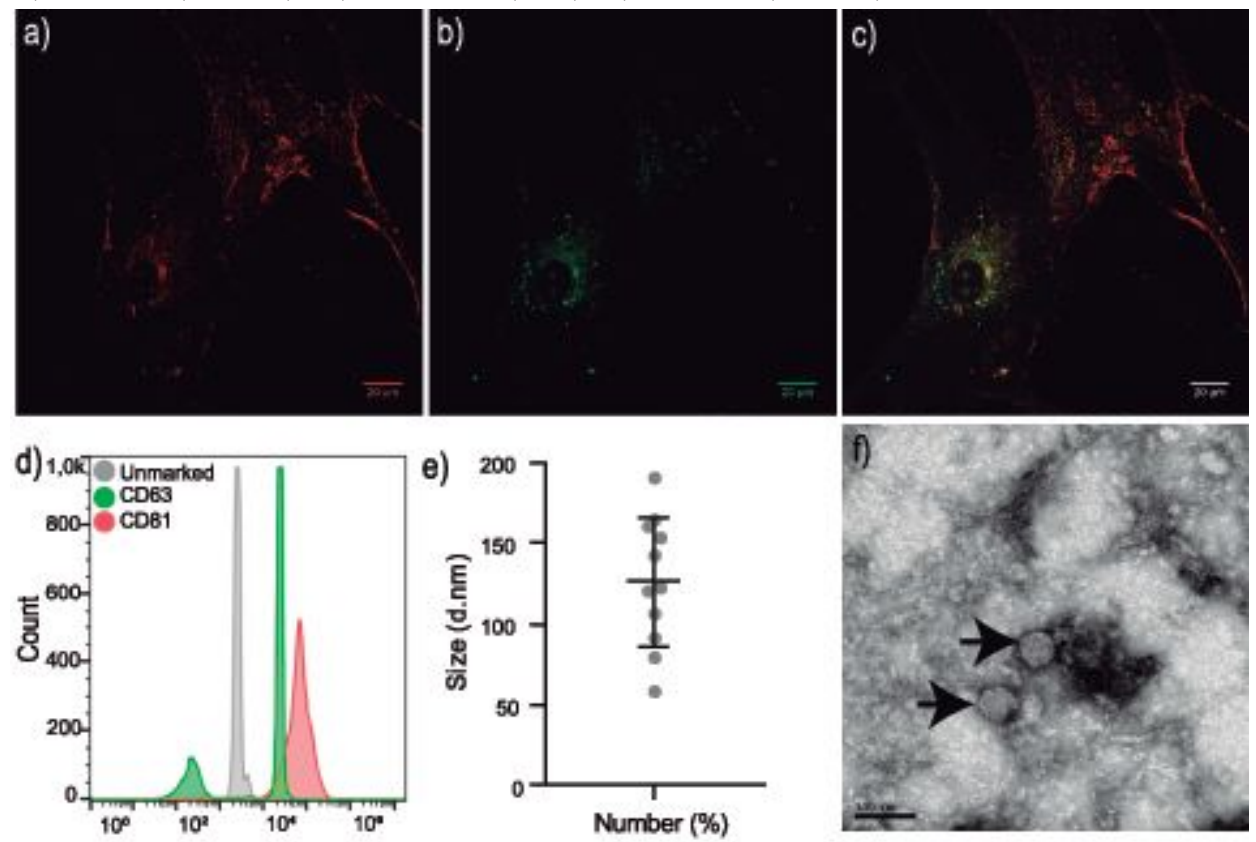


\section{Figure 3}

$3 \mathrm{EVs}$ Characterization. The fluorescence signals of the following markers were observed inside $\mathrm{C} 0$. a) CD81 (red), b) CD63 (green), c) Merge; $\mathrm{N}=3$. The fluorescence images were from a confocal microscope, using a 60x objective. Scale bars: $20 \mu \mathrm{m}$. d) Histogram of EVs characterization by flow cytometry with specific CDs markers. The positive result (peak fluorescence shift) for CD63 is green-labeled, the positive result for CD81 is red labeled. These results were compared with EVs incubated only with beads (gray). e) Average diameter $(140 \mathrm{~nm})$ made by the Zetasizer instrument. f) Transmission electron microscopy (TEM) images by direct examination, showing purity hAT-MSC-derived EVs (black arrow); MET JEM 1200 EXII, Magnification 200k, scale bar 100nm

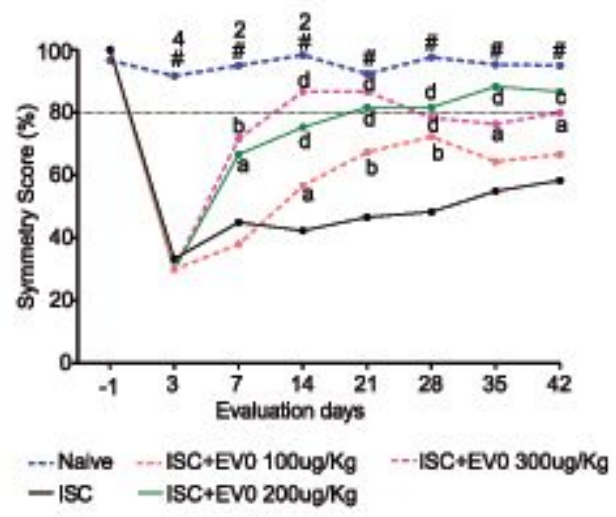

\section{Figure 4}

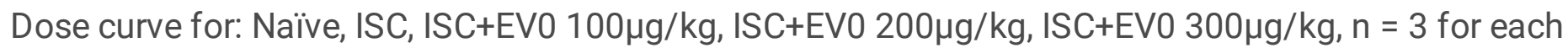
group. Day 0 refers to baseline symmetry, evaluated 24 hours before induction of stroke. Data are expressed as mean (SD were less than $32 \%$ of respective mean) and analyzed by two-way ANOVA followed by Tukey's test: ap $<0.05$, bp $<0.01, c p<0.001$ and dp $<0.0001$, compared to the ISC group; $2 p$ $<0.01,4 \mathrm{p}<0.0001$, compared to $200 \mu \mathrm{g} / \mathrm{Kg}$ and $300 \mu \mathrm{g} / \mathrm{Kg}$ group. $\# \mathrm{p}<0.01$ compared to $100 \mu \mathrm{g} / \mathrm{Kg}$ 

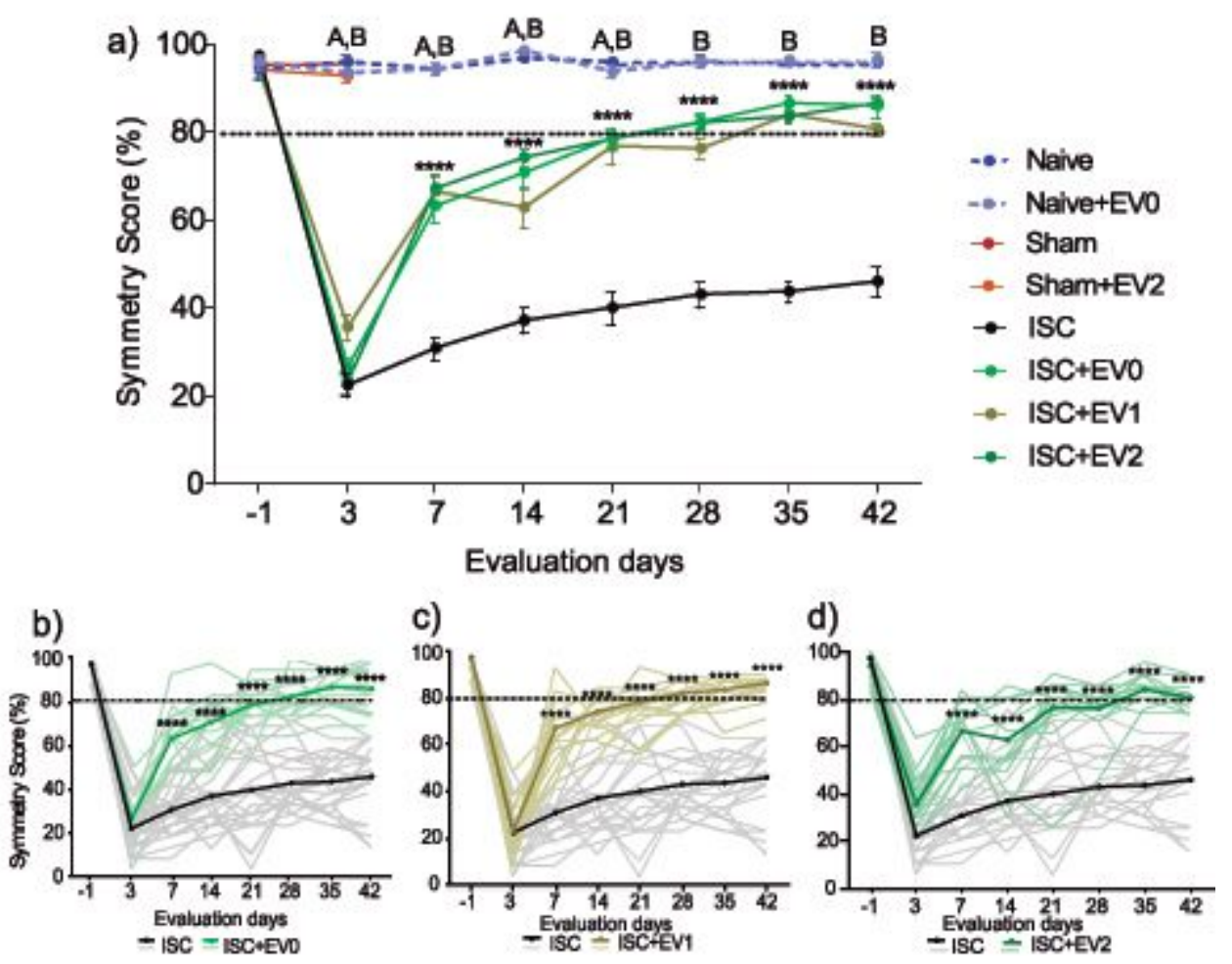

Figure 5

Symmetry score. a) The results are represented as group mean \pm SEM. $b-d$ ) The individual results are represented as group mean (dotted line and strong lines) and individual performances (soft lines). b) ISC + EV0 group compared to the ISC group. c) ISC + EV1 group compared to the ISC group. d) ISC + EV2 group compared to the ISC group. Naïve $(n=8)$, Naïve+EV0 $(n=6)$, Sham $(n=11)$, Sham+EV2 $(n=5)$, ISC $(n=22), I S C+E V 0(n=17) ;$ ISC+EV1 $(n=17) ;$ ISC+EV2 $(n=17)$. Data are expressed as mean \pm SEM, analyzed

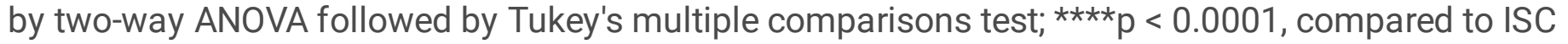
group; $A p<0.05, p<0.01, p<0.001$, or $p<0.0001$ Naïve group compared to ISC+EV groups and $B p<$ $0.05, p<0.01, p<0.001$, or $p<0.0001$ Naïve group compared to ISC group

a)
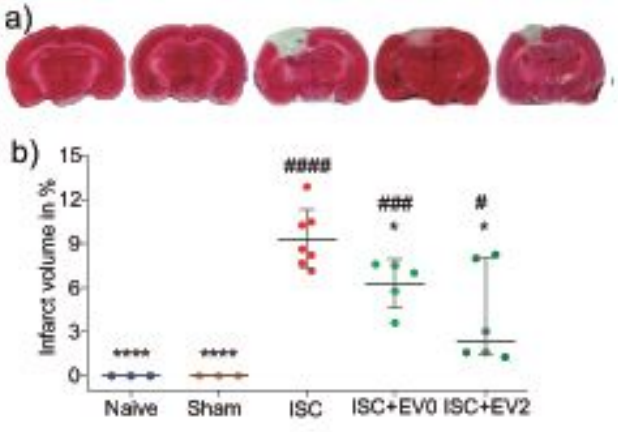

Figure 6

a) Representative images of the infarct volume (TTC staining). b) EVs treatment significantly decreases the infarct volume. For Naïve, Sham, ISC, and ISC+EVO, we used Statistical Analysis by Unpaired T-test. Data are reported as mean $\pm S D,{ }^{*} p<0.05$, ${ }^{\star \star \star \star} p<0.0001$ comparing to ISC group, \#\#\#p $<0.001$ and 
\#\#\#\#p < 0.0001 comparing to Naïve and Sham groups. For ISC+EV2, we used the Mann-Whitney test of the Unpaired t-test. Data are reported as the median with interquartile range. ${ }^{*} \mathrm{p}<0.05$ comparing to ISC and \#p $<0.05$ comparing to Naïve and Sham groups

a)

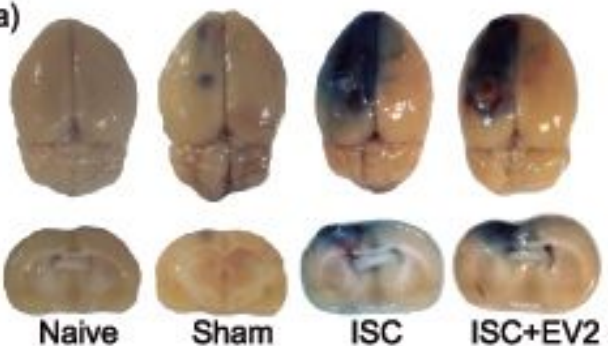

b)

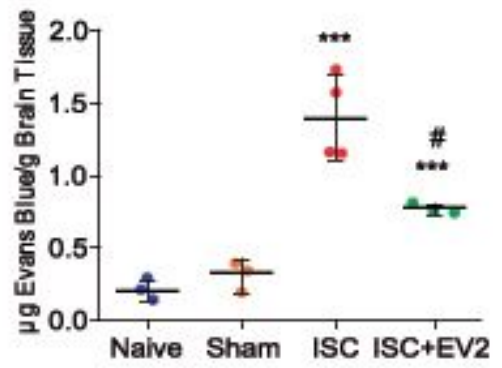

c)

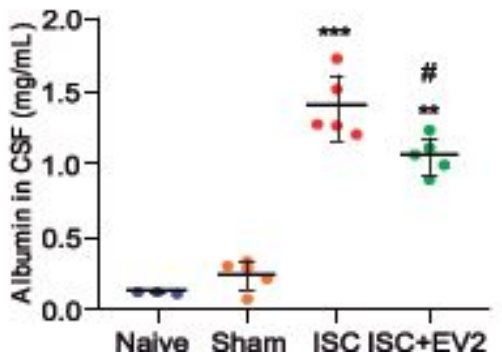

Figure 7

a) Representative Evans blue images in brain tissue; dye crosses the BBB in Sham and stroke animals. b) Colorimetric quantification of brain Evans blue. c) Albumin levels in CSF. Statistical Analysis by Unpaired t-test. Data are reported as the mean \pm S.D. ${ }^{* \star} \mathrm{p}<0.01$ and ${ }^{* \star *} \mathrm{p}<0.001$ comparing to Naïve and Sham groups, \#p < 0.05 comparing to ISC group 
a)
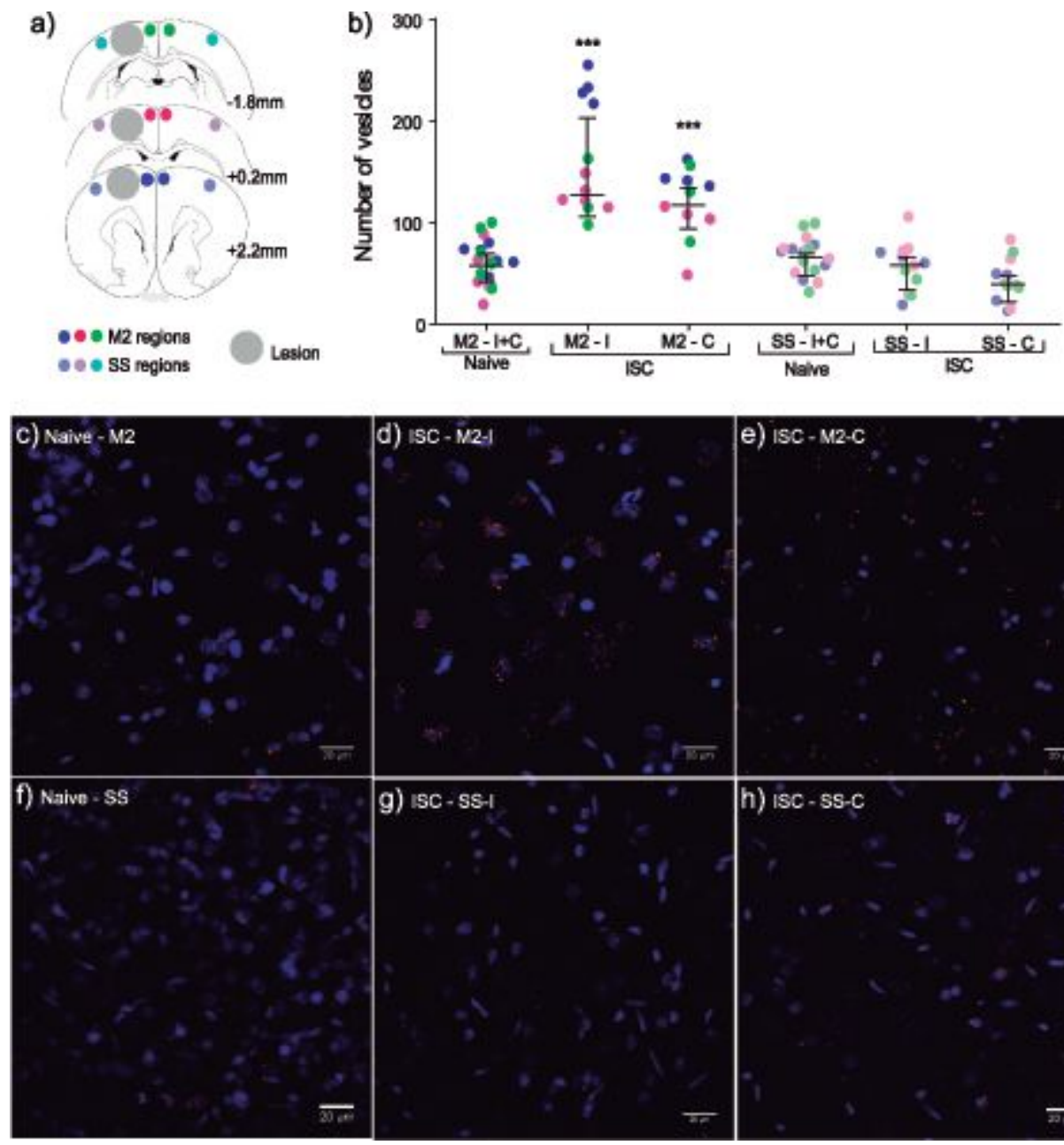

\section{Figure 8}

EVs distribution in brain cortex 18 hours after treatment. a) In a schema of the regions where the images were taken: peri-infarct region and its contralateral equivalent, supplementary motor cortex regions (M2) and somatosensory regions (SS) (+2.20mm, $0.2 \mathrm{~mm}$ and $-1.88 \mathrm{~mm}$ to Bregma), Gray=lesion. b) Graph indicating a greater number of vesicles in the ipsilateral M2 region; In c) - h) representative images of the M2 and SS regions located at $0.20 \mathrm{~mm}$ from Bregma. c) Naïve M2; d) M2 ipsilateral perinfarct region; e) M2 contralateral perinfarct region; f) Naïve SS region; g) SS ipsilateral perinfarct region; $h$ ) SS contralateral perinfarct region. Counting the EVs was performed using ImageJ software. Statistical Analysis by Mann Whitney test. Data are reported as the Medians and interquartile ranges. ${ }^{*} \star \star x p<0.0001$ comparing M2-I and M2-C to all other groups, $\mathrm{N}=3,3$ sections in each rat per group. Scale bars: $20 \mu \mathrm{m}$ 

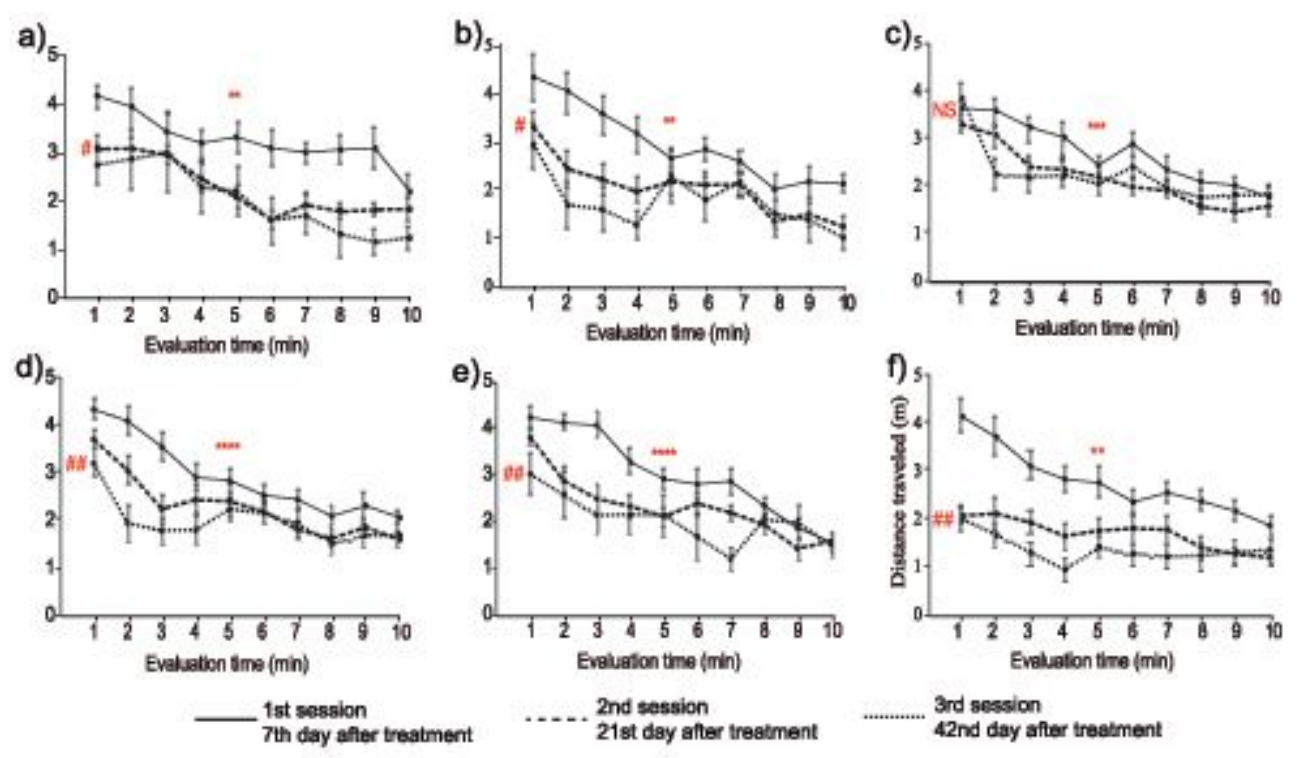

Figure 9

Open Field Task. Groups: a) Naïve (n=8), b) Naïve+EVO (n=6), c) ISC ( $n=16)$, d) ISC+EV0 (n=16), e) ISC+EV1 $(n=15)$, and f) ISC+EV2 $(n=16)$. Statistical Analysis by 2way ANOVA, followed by Tukey's

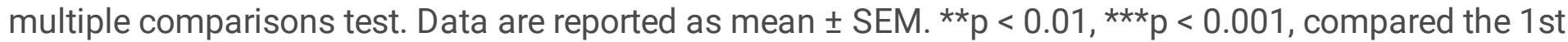
with 5th minute of the same session; \#p $<0.05, \# \# p<0.001$, compared the 1 st minute of the first session with the 1 st minute of the second/third or third sessions 
a)
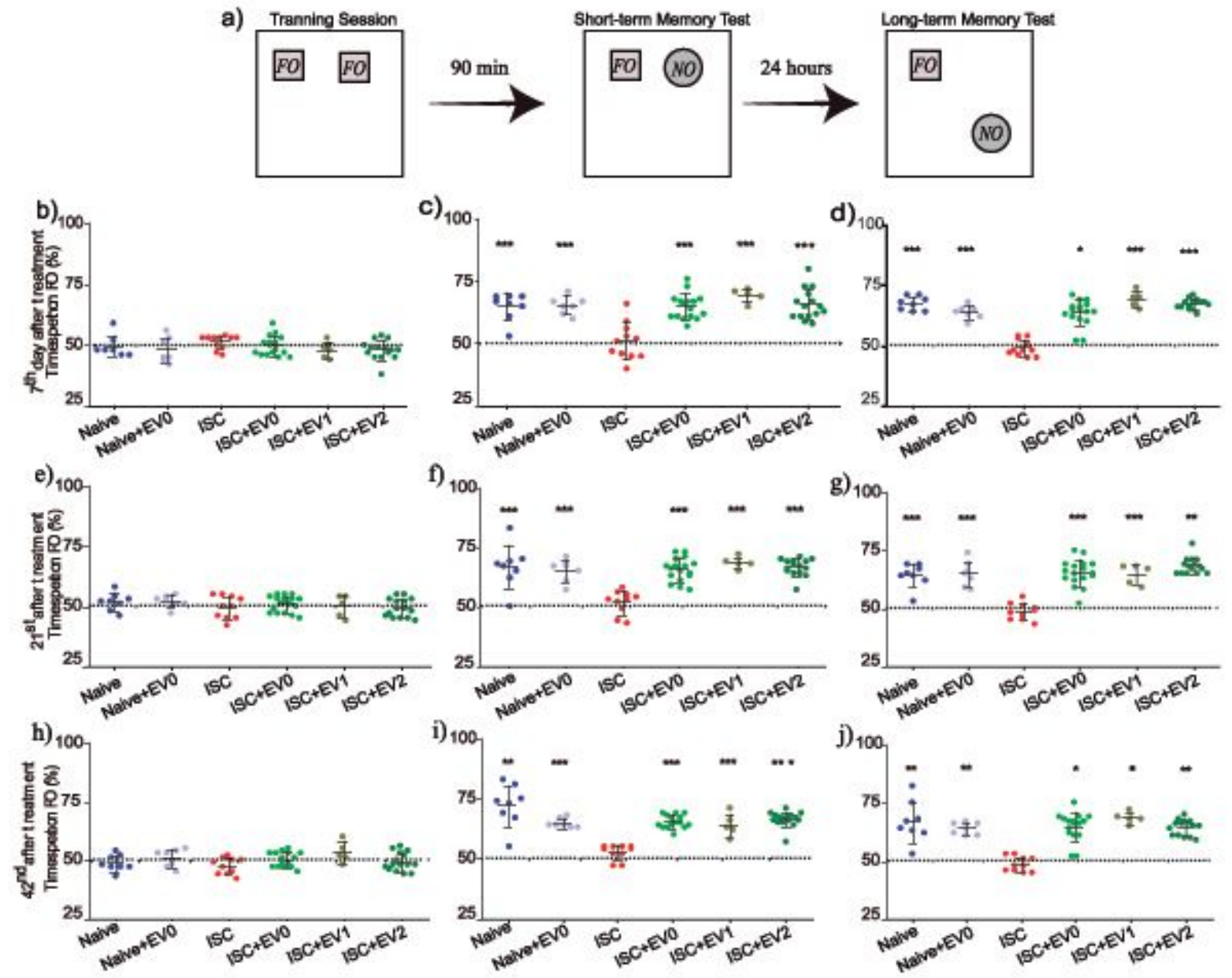

Figure 10

a) Scheme of the protocol by using Familiar Object (FO) and/or Novel Object (NO). Groups: Naïve ( $n=8)$, Naïve+EVO $(n=7)$, ISC $(n=16)$, ISC+EVO $(n=16)$, ISC+EV1 $(n=5)$, and ISC+EV2 $(n=16)$. Training sessions (TS) using 2 FOs; Short Term Memory test sessions 90 minutes after and Long-Term Memory test sessions 24 hours after TS. b, e, and h) 3 successive training sessions; $c$, $f$ and i) 3 successive test STM sessions; $d, g$ and j) 3 successive test LTM sessions. Unpaired T-test with a theoretical average of $50 \%$. Data reported as mean \pm S.D.; ${ }^{*} p<0.05,{ }^{* \star} p<0.01$, and ${ }^{* \star *} p<0.001$, compared to the theoretical average of $50 \%$

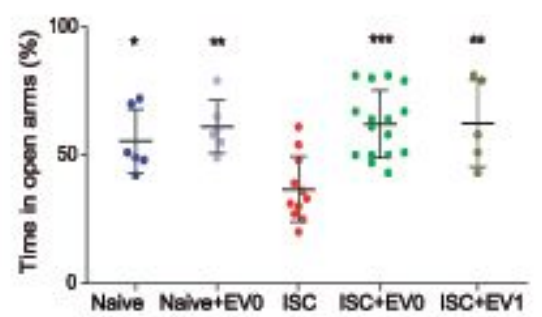

Figure 11 
Elevated plus-maze task. Groups: Naïve (n=6), Naïve+EVO (n=6), ISC (n=11), ISC+EV0 ( $n=16)$, and ISC+EV1 $(n=5)$. Statistical analysis by Unpaired T-test. Data are reported as mean $\pm S D,{ }^{*} p<0.05, * * p<$ $0.01, * * * p<0.001$, compared to ISC group

a)

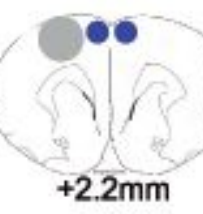

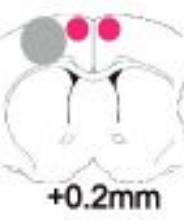
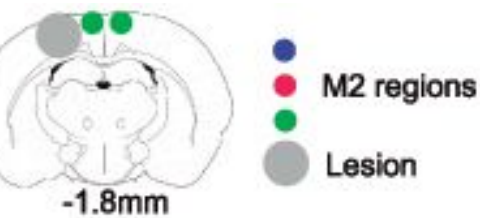

b)
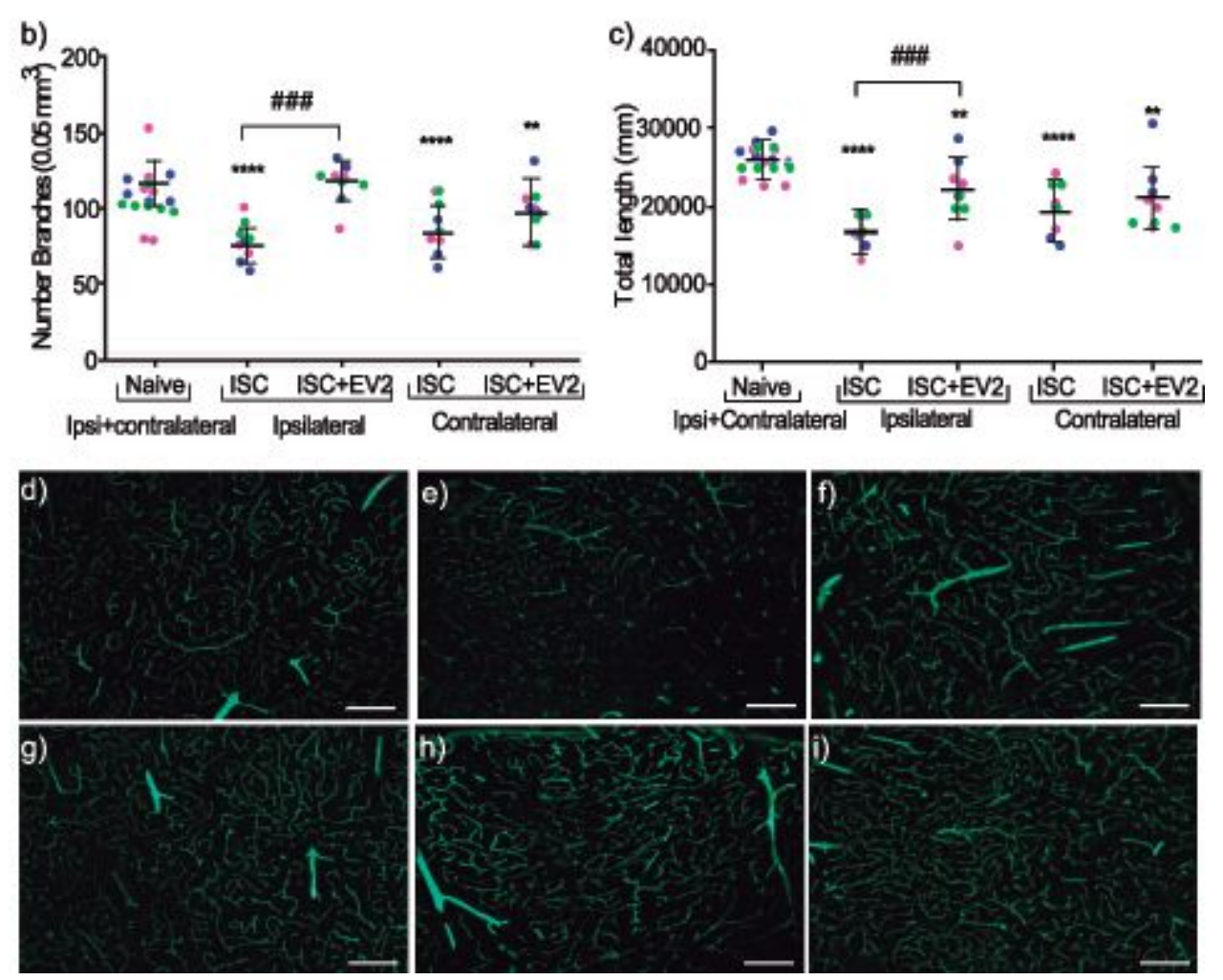

\section{Figure 12}

Analysis of blood vessels. a) a scheme of the regions where the images: peri-infarct region and its contralateral equivalent $(+2.20 \mathrm{~mm},+0.2 \mathrm{~mm}$ and $-1.88 \mathrm{~mm}$ of Bregma); b) Number of branches of the M2 regions; c) Total length of the $\mathrm{M} 2$ regions; $\mathrm{d}$ - i) Representative images of the $\mathrm{M} 2$ regions located at $+0.20 \mathrm{~mm}$ from Bregma: d) Naïve M2 ipsilateral region, e) ISC M2 ipsilateral region; f) ISC+EV2 M2 ipsilateral region; g) Naïve M2 contralateral region; h) ISC M2 contralateral region; i) ISC+EV2 M2 contralateral region. Statistical Analysis by Unpaired T-test. Data are reported as the mean \pm S.D. ${ }^{\star \star \star \star} p<$ 0.0001 comparing to naïve group, \#\#\#p 0.001 comparing ISC group. $N=3,3$ sections in each rat per group. Scale bars: $20 \mu \mathrm{m}$

\section{Supplementary Files}

This is a list of supplementary files associated with this preprint. Click to download.

- Supplementaryinformation1.mp4 
- SupplementaryInformation2.pdf

Page 28/28 